\title{
Exceptional Arabic Diminutive Forms of Nouns with $[a a]$ : An Optimality-Theoretic Analysis
}

\author{
Albatool Mohammed Abalkheel ${ }^{1}$ \\ ${ }^{1}$ Department of English Language and Translation, College of Arabic Language and Social Studies, Buraydah, \\ Qassim University, Saudi Arabia \\ Correspondence: Albatool Mohammed Abalkheel, Department of English Language and Translation, College of \\ Arabic Language and Social Studies, Buraydah, Qassim University, Saudi Arabia. E-mail: a.abalkheel@qu.edu.sa
}

\author{
Received: May 13, $2020 \quad$ Accepted: June 17, $2020 \quad$ Online Published: June 29, 2020 \\ doi:10.5539/ijel.v10n5p68 URL: https://doi.org/10.5539/ijel.v10n5p68
}

\begin{abstract}
Most diminutive forms in Arabic adhere in their derivation to certain simple phonological and morphological processes without any complications. However, there are exceptions to be found, including diminutive forms of nouns with [aa] in which the segment [w] surfaces. Using Optimality Theory (OT) as a framework and using syllable weight as a base of analysis, this study aims to provide an accurate explanation of such phenomena. This work will show that the root of words with [w] is not simply biconsonantal with an emphatic segment (i.e., [w]) inserted to fill the empty onset. Instead, the root is triconsonantal in which [w] is an essential segment. It also reveals that syllable-weight constraint is inviolable in Arabic dialects.
\end{abstract}

Keywords: diminutives, optimality theory, Standard Arabic, disyllabic bases

\section{Introduction}

Arabic has different diminutive forms that express different meanings, including: smallness, familiarity, endearment, and contempt. The morphological process the diminutive forms in Standard Arabic (henceforth SA) undergo is usually viewed as a simple derivation process that maps root consonants onto well-defined positions of diminutive patterns, depending upon certain phonological principles. The input includes $/ a \mathrm{u} j /$, the consonantal root, and the consonantal base. However, Arabic diminutive forms exhibit some exceptional cases, including those with $/ \mathrm{w} /$ in the middle, like mwijl [a small amount of money] from maal [money]. This paper is designed to examine this case within the Optimality Theory (OT) framework as a syllable-related phenomenon, revealing that the root of words with [w] is not simply biconsonantal with an emphatic segment (i.e., [w]) inserted to fill the empty onset. Using data from the author's native dialect, Qassimi Arabic (henceforth QA), which is one of the Najd dialects (that are close in their phonological and morphological structures to SA), and which is based on syllable-weight, we will show that such words have triconsonantal roots of which [w] is a part. This highlights that syllable-weight constraint, which requires all syllables be bimoraic, is inviolable in Arabic dialects.

\section{Theoretical Background}

Diminutive forms are linguistic items used in almost every language, including Arabic (Azieb \& Mahadin, 2015; Bauer, 1997; Jurafsky, 1996; Muho, 2019). The phenomenon exists in almost all Arabic dialects, such as Libyan Arabic (Gadoua \& Davis, 2019), the Arabic dialect of Tunis (Procházka, 2017), Najdi/Hā'ili Arabic (Alshammari \& Davis, 2019), and Qassimi Arabic (Al-Rojaie, 2012), among others. As Ibn 'Usfur (1972) stated, diminutive forms in Arabic are used to mean: (a) minimizing the number of something as in tumajraat (a few dates), (b) minimizing the status of someone or something, as in kuwajtib [a less well-known writer] and kutajib [a short book], (c) to show contempt, as in rudzail [a little man], (d) an approximation of time, as in qubajl (a little before) and buSajd [a little after], or (e) an approximation of place, as in fuwajq [a little above]. Al-Ghalayīni (2002) added the use when stating a term of endearment and affection, as in bunaj [my little son].

Generally speaking, singular nouns in SA have one of the syllable structures as presented in Table 1. 
Table 1. Standard Arabic singular nouns syllable structure

\begin{tabular}{|c|c|c|}
\hline Noun Class & Syllable Structure & Example \\
\hline a. Noun of Instrument & miC.CāC & $m u f . t a \bar{\hbar}[\mathrm{key}]$ \\
\hline \multirow[t]{2}{*}{ b. Noun of Place } & $\mathrm{maC} . \mathrm{CaC}$ & mak.tab[place of writing - office] \\
\hline & maC.CiC & mas.dzid [place of kneeling- mosque] \\
\hline \multirow[t]{4}{*}{ c. Primitive noun or abstract verbal noun } & $\mathrm{Ca} . \mathrm{CaC}$ & wa.lad [boy] \\
\hline & Ci.CaC & $d_{3}$ a.bal [mountain] \\
\hline & Ca.CiC & najm $[$ star $]$ \\
\hline & Ci.CiC & fikr [thinking] \\
\hline \multirow[t]{2}{*}{ d. Occupational or Active participle } & CaC.CaaC & ћam.maal [porter] \\
\hline & $\mathrm{Caa}, \mathrm{CiC}$ & Saa.mil [worker] \\
\hline e. Passive participle & maC.CuuC & mas.muић[permitted] \\
\hline \multirow[t]{2}{*}{ f. Abstract noun from adjective } & Ci.CiC & $\operatorname{fibr}[$ size $]$ \\
\hline & $\mathrm{CaCaaCeh}$ & $d^{\text {`a.raa.fah [daintiness] }}$ \\
\hline \multirow[t]{3}{*}{ g. Comparative adjective and color and physical defect words } & $\mathrm{PaC} \cdot \mathrm{CaC}$ & Pak.bar[bigger] \\
\hline & & Pas.wad [black] \\
\hline & & PaO.wal [disease of sheep] \\
\hline
\end{tabular}

Most Arab grammarians (e.g., Al-Ghalayīni, 2002; Sībawayhi, 1999, and others) view the process of forming the different diminutive forms as a derivation based on the following three basic conjugations: fuSayl for a triconsonantal noun, fuSaySil for a quadriconsonantal noun with a short-vowelled second syllable, and fuSaySiil for a quinquecinsonantal noun with a short-vowelled second syllable. These conjugations are shown with examples in Table 2.

Table 2. Diminutive conjugation and examples

\begin{tabular}{|c|c|c|c|}
\hline \multirow[t]{2}{*}{ Root Type } & \multirow[t]{2}{*}{ Diminutive Conjugation } & \multicolumn{2}{|l|}{ Example } \\
\hline & & Non-Diminutive & Diminutive \\
\hline \multirow[t]{3}{*}{ a. Triconsonantal } & \multirow[t]{3}{*}{ fu.Sail } & qa.mar $[\mathrm{moon}]$ & qu.majr [little moon] \\
\hline & & kalb $[\mathrm{dog}]$ & ku.lajb [little dog] \\
\hline & & nahr [river] & nu.hajr [little river] \\
\hline \multirow{3}{*}{$\begin{array}{l}\text { b. Quadriconsonantal noun with a } \\
\text { short-vowelled second syllable }\end{array}$} & \multirow[t]{3}{*}{ fu.Saj.Sil } & Saq.rab [scorpion] & Su.qaj.rib [small scorpion] \\
\hline & & dir.ham [drachma] & du.raj.him [little drachma] \\
\hline & & Sal.qam [bitterness] & Su.laj.qim [little bitterness] \\
\hline \multirow{3}{*}{$\begin{array}{l}\text { c. Quadriconsonantal noun with a } \\
\text { long-vowelled second syllable }\end{array}$} & \multirow[t]{3}{*}{ fu.Saj.Siil } & Sus ${ }^{\varsigma}$ fuur $[$ sparrow] & Su.s`aj.fiir [small sparrow] \\
\hline & & sul.t'aan [sultaan] & 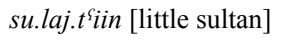 \\
\hline & & mis.baah [lamp] & mи.s'aj.biiћ [[little lamp] \\
\hline
\end{tabular}

However, Traditional Analysis of Arabic diminutive forms has some exceptional cases, which are presented in Table 3. These diminutive forms have their own conjugations, whereas forms in $3 a, 3 b$ and $3 c$ are trisyllabic, such as those that have the conjugation fuSajSil, but they have [w], which does not have a correspondent in the related non-diminutive forms. The non-diminutive forms of the diminutive forms in $3 \mathrm{~d}$ and $3 \mathrm{e}$ are triconsonantal. They have the diminutive conjugation fuSajl that preserves the last vowel of the bases.

Table 3. Standard Arabic exceptional diminutive forms

\begin{tabular}{|c|c|}
\hline Non-diminutive & Diminutive \\
\hline a. faa.Sir [poet] & fu.waj.Gir \\
\hline b. qaa.rib [boat] & qu.waj.rib \\
\hline c. $b a a b$ [door] & bu.wajb \\
\hline d. $\hbar u d\} . r a$ [room] & $\hbar$ ћ.dzaj.ra \\
\hline e. $s i b . \gamma a$ [paint] & su.baj.za \\
\hline
\end{tabular}

To overcome this drawback of Traditional Analysis, some Arab linguists (e.g., Ismail, 2012; Rashid, 2010) have analyzed the linguistic phenomenon of diminution within the framework of OT. However, the process in Arabic has not received ample attention in the literature of the theory as yet (Azieb \& Mahadin, 2015). The case of 
nouns with [aa] in their base and [w] in their diminutive forms, specifically, is still debated. Considering [w] as an epenthetic segment that is controlled by the constraint DEP -PL(ACE), as Ismail (2012) argued, would not be able to eliminate the presence of $[\mathrm{w}]$ in some Arabic dialects, such as Qassimi Arabic, which is similar to Standard Arabic. Hence, this paper considers the effects of the syllable and its weight to resolve the issue. Syllable has its role in phonology and its analytic frameworks as a referential domain in phonotactic constraints (Fudge, 1969; Selkirk, 1982) and one with applications for phonological processes (Blevins, 1995; Selkirk, 1982). Syllable effects can be seen and represented by the weight that has been accounted for within moraic theory (McCarthy \& Prince, 1986) to distinguish between light, heavy, and super heavy syllables, depending upon the number of moras each syllable has.

\section{An Optimality-Theoretic Analysis}

Diminutive forms are formed in Arabic through an output-based process where they are "derived from bases that exist as independent words (typically nouns) in the language" (Ismail, 2012, p. 189), especially with having parts of the base preserved in the diminutive forms. The formation of the diminutive in SA also involves taking the entire base (the consonantal root) as input: $d^{\top} a m$, the first consonant of the base (i.e., an apostrophe-like shape written above the consonant which precedes it in pronunciation to represent the short vowel; /u/), fath the second consonant (a diagonal stroke written above the consonant, which precedes it in pronunciation to represent the short vowel /a/); and, inserting /j/ after it. For example, to derive the diminutive form nuhajr [little river] from $n a h r$ [river], the following steps should be followed:

1) $D^{\varsigma}$ am the first consonant

[nahr] $\rightarrow /$ nuhr/

2) Fath the second syllable

/nuhr / $\rightarrow$ /nuhar/

3) Inserting $/ \mathrm{j} /$ after the second consonant

/nuhar/ $\rightarrow$ [nuhajr]

Nouns with medial [aa] have [w] in their diminutive forms, like mwijl [a small amount of money] from maal [money]. It might be said that [w] is an emphatic segment that is inserted to fill the empty onset. In terms of OT, the candidate with the epenthetic segment $[\mathrm{w}]$ wins in the case of SA, because it surfaces in the related diminutive forms to minimize the violation of syllabic well-formedness and because it satisfies the constraint DEP - PL(ACE) that requires inserting the least expensive epenthetic segment.

(a) DEP-PL(ACE): An epenthetic segment must not have independent place features of its own

However, this constraint above in (a) cannot eliminate the presence of [w] in some Arabic dialects, like Qassimi Arabic which is very similar to Standard Arabic.

\subsection{Qassimi Dialect and Its Diminutive Forms}

As a native speaker of both QA and SA, I argue that analyzing diminutive forms in QA according to Traditional Analysis has the same exceptional cases, as presented in Table 4.

Table 4. Standard Arabic and Qassimi Arabic exceptional diminutive forms

\begin{tabular}{|c|c|c|c|}
\hline \multicolumn{2}{|l|}{ SA } & \multicolumn{2}{|l|}{ QA } \\
\hline Non-diminutive & Diminutive & Non-diminutive & Diminutive \\
\hline a. Saa.Sir [poet] & fu.waj.Sir & faa.Sir & Pif.wij.Sir \\
\hline b. qaa.rib [boat] & qu.waj.rib & qaa.rib & Piq.wij.rib \\
\hline c. $b a a b$ [door] & bu.wajb & baab & Pib.wijb \\
\hline d. $\hbar u d z . r a[$ room] & ћu.dzaj.ra & 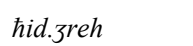 & Piћ.dzij.reh \\
\hline e. $s i b . \gamma a$ [paint] & su.baj.ya & sib.yeh & Pis.bij.yeh \\
\hline
\end{tabular}

Before providing this novel analysis, I would like to note that I disagree with the phonological representation of $\hbar u d_{3} \mathrm{ra}$ - and words that end in [a] in general - that Ismail (2012) provided. These should be represented with a final [h] after the [a] because SA typically does not allow dropping the final consonant, and with the feminine

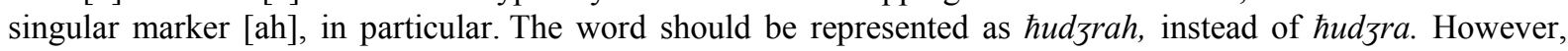
because the scope of this paper is diminutive forms, I will keep such words in SA with the final [a] to maintain Ismail's assertion, especially because such a representation does not affect the ranking of constraints that 
accounts for the optimal candidate.

In the case of QA, $[\mathrm{w}]$ surfaces in the related diminutive forms of nouns with medial [aa]. More examples are given in Table 5.

Table 5. Examples of Qassimi diminutive forms with [w]

\begin{tabular}{ll}
\hline Noun & Diminutive Form \\
\hline baab [door] & Pab.wijb [little door] \\
maal [money] & Pam.wijl [a small amount of money] \\
naar [fire] & Pan.wijr [little fire] \\
dzaal [side of a place or a road] & Pad3.wijl [little side] \\
\hline
\end{tabular}

Like SA, the QA syllable template requires an obligatory onset, but adding DEP - PL(ACE) to the undominated constraints in the set gives a wrong sinning candidate, as shown in Table 6.

Tableau 6. Analysis after adding DEP-PL(ACE) to the undominated constraints in Qassimi dialect

\begin{tabular}{|c|c|c|c|c|c|c|c|c|c|c|c|}
\hline $\begin{array}{l}\text { Input: } / \text { i i j/ + /ml/ } \\
\text { Base [maal] }\end{array}$ & $\begin{array}{l}0 \\
Z \\
\text { 足 } \\
\text { 第 }\end{array}$ & 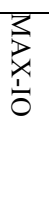 & $\begin{array}{l}{ }_{2}^{*} \\
0 \\
3 \\
\vdots \\
\vdots\end{array}$ & 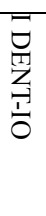 & 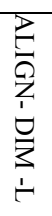 & 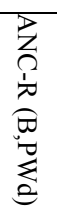 & 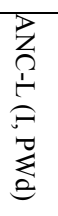 & 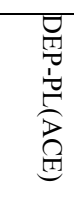 & 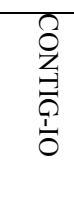 & 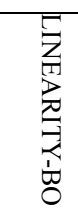 & $\begin{array}{l}\nabla \\
\stackrel{T}{T} \\
\stackrel{1}{0} \\
0 \\
0\end{array}$ \\
\hline a. Pam.Paijl & & & & & & & & $* !$ & $* * *$ & * & $* * * *$ \\
\hline :b. Pam.waijl & & & & & & & & & $* * *$ & * & ***** \\
\hline
\end{tabular}

Tableau 6 shows that by adding this constraint, it is possible to predict the appropriate epenthetic segment, but the winner candidate is still not the optimal one because it has a medial [a] after the epenthetic [w]. The way traditional Arabic linguists (e.g., Sibawayh) classify consonantal roots solves the problem. These scholars state that the consonantal root of maal is $/ \mathrm{mwl} /$. I argue that there is no noun in SA with a biconsonantal root. When the noun maal is derived from its consonantal root, the [w] is deleted. I propose that to derive a noun using the conjugation $f a$ ?al from a consonantal root with a medial glide (i.e., [w] or [y]), the glide is deleted to obey the syllable-weight constraint.

Below, on Table 7, is a set of examples showing deletion of [w] when /aa/ is inserted to derive nouns, and retention of $[\mathrm{w}]$ when deriving accusative past tense verbs using the conjugation fa? $\mathrm{Pal}$. It is important to note that the same nouns and verbs are used in both SA and QA, as there is no dialectal variation with these nouns.

Table 7. Examples of derivations with and without $[\mathrm{w}]$

\begin{tabular}{lll}
\hline Consonantal Root & Noun & Verb [accusative past tense] \\
\hline$/ \mathrm{mwl} /$ & maal 'money' & maw.wal [funded] \\
$/ \mathrm{nwr} /$ & naar 'fire' & naw.war [added lights to the place] \\
$/ \mathrm{d} 3 \mathrm{wl} /$ & dzaal [side of a place or a road] & dzaw.wal [walked someone] \\
\hline
\end{tabular}

These past tense forms of accusative verbs show [w] is part of the consonantal root of the noun with /aa/. In the traditional method of Arabic linguists, conjugation of the accusative past tense is faৎ̧al, where the second consonant is geminated. In all these examples, $[\mathrm{w}]$ is geminated. In Optimality Theory, this means that MAX-C is dominated in Arabic in some environments. This is a rejection of several Abu Mansour (1995) assumptions, including that this constraint is undominated because of the unique role of consonants in Arabic. These nouns are derived from their consonantal roots through mapping /aa/ into these consonants where the first $/ \mathrm{a} /$ is inserted after the second consonant and the second $/ \mathrm{a} /$ is inserted after the third consonant. In this analysis, I assume that this formation process is an input-base process. To obtain the optimal candidate, /aa/ must be mapped onto the consonantal root.

Therefore, MAX-IO dominates DEP-BO to preserve segment correspondence. Another correspondence constraint (IDENT-IO) is obeyed to prevent any change in features, and ANCHOR-BO is obeyed to ensure that 
the input segments do not appear on the edges. ONSET is also obligatory in Arabic. This ranking is shown in (b), below, and tested in Tableau 8 .

(b) ONSET, MAX-IO, IDENT-IO, ANCHOR-BO >> DEP-BO

Tableau 8. Analysis of diminutives after adding IDENT-IO

\begin{tabular}{|c|c|c|c|c|c|}
\hline $\begin{array}{l}\text { Input: /aa/ } \\
\text { Base /qbs/ }\end{array}$ & ONSET & MAX-IO & IDENT-IO & ANCHOR-BO & DEP-BO \\
\hline a. qabas & & & & & $*$ \\
\hline b. qubas & & & $* !$ & & * \\
\hline c. Qabsa & & & & $* !$ & $*$ \\
\hline d. Qbs & & $* ! *$ & & & \\
\hline
\end{tabular}

Candidate $8 \mathrm{a}$ is the optimal candidate because it satisfies all highly ranked constraints. Candidates $8 \mathrm{~b}, 8 \mathrm{c}$, and $8 \mathrm{~d}$ are ruled out because they violate IDENT-IO, ANCHOR-BO, and MAX-IO, respectively.

In the case of deriving maal from $/ \mathrm{mwl} /$, the winning candidate with this ranking would be $* / \mathrm{maw} . \mathrm{al} /$. However, such a word violates the syllabic well-formedness constraint ONSET. Assuming the consonantal root is $/ \mathrm{mwl} /$, the more accurate way to justify the deletion of the segment $[\mathrm{w}]$ is with syllable-weight. The majority of constraint-based research on Arabic dialects (e.g., Bamakhramah, 2010; Watson, 2007), has found that the syllable-weight constraint that requires all syllables be bimoraic is inviolable in Arabic dialects.

The constraint $* 3 \mu$, which requires syllables to be maximally bimoraic and prohibits trimoraic syllables is undominated.

(c) $*[3 \mu]$ : No trimoraic syllables (Kager, 1999, p. 268)

To satisfy this constraint, the long vowel in the initial syllable is shortened. Therefore, this constraint dominates MAX-V-IO, while MAX-C-IO should remain undominated. As Al Motairi (2015) noted, CVC syllables are treated as heavy syllables when they are not the final syllable because of the constraint WEIGHT-BY-POSITION (WBP).

(d) WBP: Coda consonants are moraic

Therefore, the WBP constraint must be active in the grammar of Qassimi Arabic. When CVC, CVVC occur finally, they are also bimoraic. This is because the final $\mathrm{C}$ is mora-less where it counts as a peripheral extra prosodic element, satisfying the undominated constraint *F INAL-C- $\mu$.

(e) *F INAL-C- $\mu$ : The final consonant is mora-less.

The CONTIGUITY constraint as well as * $[3 \mu]$ and *F INAL-C- $\mu$, outrank WBP in QA (Al Motairi, 2015). NOSHAREDMORA ( $\mathrm{NS} \mu$ ) is also part of the set of undominated constraints in Qassimi Arabic.

(f) $(\mathrm{NS} \mu$ ): Moras should be linked to single segments (Broselow et al., 1992).

Because QA does not permit non-final CVVC syllables, NS $\mu$ is ranked high. The overall constraint hierarchy developed so far is given below $(\mathrm{g})$ and tested in Tableau 9.

(g) *FINAL-C- $\mu, *[3 \mu]$, NS $\mu$, ONSET, *Com ${ }_{\text {ONSET }}$ IDENT-IO, ANC-R (B, PWd), ANC-L (I, PWd), ALIGN $\underline{\text { DIM-L, MAX-C-IO }}>>$ MAX-V-IO $>>\underline{\text { CONTIG-IO }}>>$ WBP $>>$ LINEARITY-BO, DEP-BO

In the above ranking, constraints whose job and ranking have already been established are underlined as a means of clarification and are not included in Tableau 9. 
Tableau 9. Weight analysis

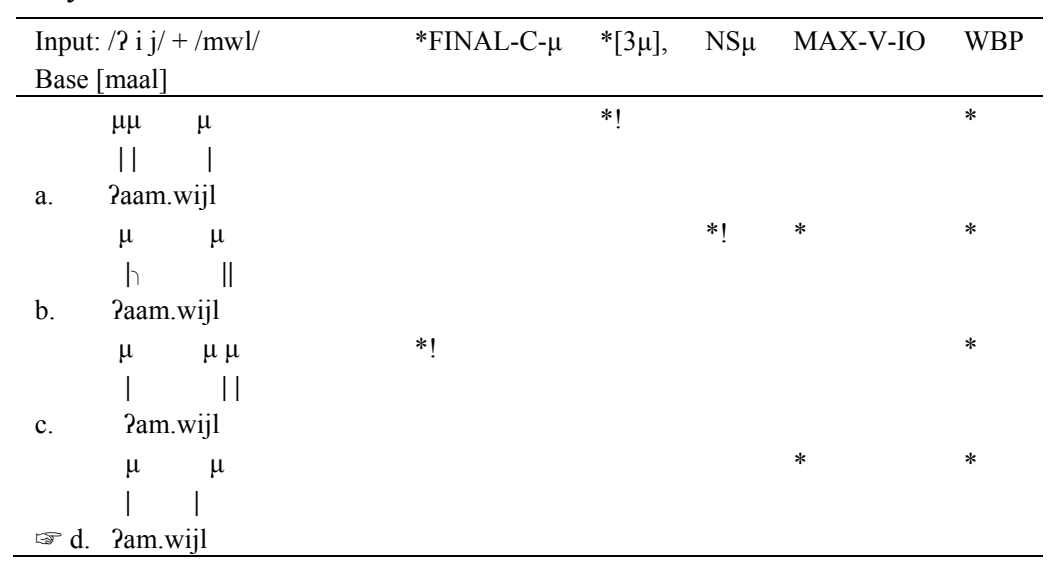

As seen in Tableau 9, the optimal candidate 9d satisfies the undominated constraints *FNAL-C- $\mu$, $*[3 \mu]$, and $\mathrm{NS} \mu$. The table also shows that candidates $9 \mathrm{a}, 9 \mathrm{~b}$, and $9 \mathrm{c}$, are ruled out immediately by the undominated constraint *FNAL-C- $\mu, *[3 \mu]$, and NS $\mu$, respectively. Therefore, analyzing nouns with [aa] in the basic forms and $[\mathrm{w}]$ in their diminutive forms is accounted for in terms of syllable weight. It clarifies that $[\mathrm{w}]$ is part of the consonantal root, not an epenthetic segment.

\section{Conclusion}

The case of exceptional Arabic diminutive forms with [w] that has been debatable has been clarified in this analysis by using syllable weight within the framework of Optimality Theory. This analysis establishes that the root of words with $[\mathrm{w}]$ is not simply biconsonantal with an emphatic segment (i.e., [w]) inserted to fill the empty onset. Instead, the root is triconsonantal, where $[\mathrm{w}]$ is an essential segment. It also reveals that syllable-weight constraint is inviolable in Arabic dialects, rejecting Abu Mansour's (1995) argument.

\section{References}

Abu-Mansour, M. (1995). Optimality and conspiracy in syllable structure of Arabic. In J. N. Beckman, L. W. Dickey \& S. Urbanczyk (Eds.), Papers in optimality theory: University of Massachusetts occasional papers 18 (pp. 1-20). GLSA.

Al Motairi, S. (2015). An optimality-theoretic analysis of syllable structure in Qassimi Arabic. Master's thesis, Eastern Michigan University. Digital Commons @EMU. Retrieved from https://commons.emich.edu/theses/612/

Al-Ghalayini, M. (2002). Complete collection of Arabic lessons (Jaami’ Al-Duruus Al-'abijjah). Daar Al-Kutub Al-'ilmijjat.

Al-Rojaie, Y. I. (2012). Diminutives in Najdi Arabic: An account of socio-pragmatic variation. Journal of Human and Administrative Sciences, 201(1091), 1-55. https://doi.org/10.12816/0003656

Alshammari, W., \& Davis, S. (2019). Diminutive and augmentative formation in northern Najdi/Hā'ili Arabic. In A. Khalfaoui \& Y. A. Haddad (Eds.), Perspectives on Arabic linguistics 31: Papers from the annual symposium on Arabic linguistics, Norman, Oklahoma (2017, Vol. 8, pp. 51-73). John Benjamins. https://doi.org/10.1075/sal.8.03als

Azieb, S., \& Mahadin, R. (2015). Noun diminutive formation in Algerian Arabic as used in Jijel: An optimality analysis. International Journal of Humanities and Social Science, 5(12), 148-157. Retrieved from https://www.researchgate.net/publication/335973868_Noun_Diminutive_Formation_in_Algerian_Arabic_a s_Used_in_Jijel_An_Optimality_Analysis

Bamakhramah, M. A. (2010). Syllable structure in Arabic varieties with a focus on super-heavy syllables. Doctoral dissertation, Indiana University. Retrieved from https://eric.ed.gov/?id=ED513552

Bauer, L. (1997). Evaluative morphology: In search of universals. Studies in Language, 21(3), 533-575. https://doi.org/10.1075/sl.21.3.04bau

Blevins, J. (1995). The syllable in phonological theory. In J. A. Goldsmith (Ed.), The handbook of phonological theory (pp. 206-244). Blackwell. https://doi.org/10.1111/b.9780631201267.1996.00008.x 
Broselow, E. (1992). Parametric variation in Arabic dialect phonology. In E. Broselow, M. Eid \& J. J. McCarthy (Eds.), Perspectives on Arabic linguistics (Vol. 6, pp. 7-45). John Benjamins. https://doi.org/10.1075/cilt.85.04bro

Fudge, E. C. (1969). Syllables. Journal of Linguistics, 5(2), 253-286. https://doi.org/10.1017/S0022226700002267

Gadoua, A., \& Davis, S. (2019, July). Diminutive formation in a Libyan dialect with some phonological implications. In A. Khalfaoui \& Y. A. Haddad (Eds.), Perspectives on Arabic linguistics 31: Papers from the annual symposium on Arabic linguistics, Norman, Oklahoma (2017, Vol. 8, p. 31). John Benjamins. https://doi.org/10.1075/sal.8.02gad

Ibn-'Usfur, A. (1972). Al-Muqarrab (Vol. 1). Al-'Ani Press.

Ismail, A. M. (2012). The diminutive in Modern Standard Arabic: An optimality theoretical analysis. Canadian Social Science, 8(2), 187-196. https://doi.org/10.3968/j.css.1923669720120802.3377

Kager, R. (1999). Optimality theory. Cambridge University Press. https://doi.org/10.1017/CBO9780511812408

Jurafsky, D. (1996). Universal tendencies in the semantics of the diminutive. Language, 72(3), 533-578. https://doi.org/10.2307/416278

McCarthy, J. J., \& Prince, A. (1995). Faithfulness and reduplicative identity. Unpublished manuscript. Rutgers University. https://doi.org/doi:10.7282/T31R6NJ9

McCarthy, J., \& Prince, A. S. (1986, 1996). Prosodic morphology. Unpublished manuscript. University of Massachusetts at Amherst and Brandeis University. Retrieved from https://scholarworks.umass.edu/linguist_faculty_pubs/index.2.html\#year_1996

Muho, H. O. (2019). A comparative study of diminutive forms in English and Kurdish. Zanco Journal of Humanity Sciences, 23(1), 254-268. https://doi.org/10.21271/zjhs.23.1.17

Prince, A., \& Smolensky, P. (1993). Optimality theory: Constraint interaction in generative grammar. Blackwell.

Procházka, S. (2017). The diminutive in the Arabic dialect of Tunis. In Studies on Arabic Dialectology and Sociolinguistics: Proceedings of the 12th International Conference of AIDA held in Marseille from May 30-June 2, 2017. https://doi.org/10.4000/books.iremam.4017

Selkirk, E. (1982). The syllable. In H. Van der Hulst \& N. Smith (Eds.), The structure of phonological representations (Vol. 2, pp. 337-383). Foris.

Sībawayh, A. (1999). Al-Kitāb. Daar Al-Kutub al-'ilmijjat.

Watson, J. C. E. (2007). Syllabification patterns in Arabic dialects: Long segments and mora sharing. Phonology, 24(2), 335-356. https://doi.org/10.1017/S0952675707001224

\section{Copyrights}

Copyright for this article is retained by the author, with first publication rights granted to the journal.

This is an open-access article distributed under the terms and conditions of the Creative Commons Attribution license (http://creativecommons.org/licenses/by/4.0/). 